\title{
Epigenetic Changes Caused by Occupational Stress in Humans Revealed through Noninvasive Assessment of DNA Methylation of the Tyrosine Hydroxylase Gene
}

Miyaki $\mathrm{K}^{* 1,2}$, Suzuki $\mathrm{T}^{1,2}$, Song $\mathrm{Y}^{1}$, Tsutsumi $\mathrm{A}^{2}$, Kawakami N ${ }^{3}$, Takahashi $\mathrm{M}^{4}$, Shimazu $\mathrm{A}^{3}$, Inoue $\mathrm{A}^{5}$, Kurioka $\mathrm{S}^{6}$, Kan $\mathrm{C}^{3}$, Sasaki $\mathrm{Y}^{1}$ and Shimbo $\mathrm{T}^{1}$

${ }^{1}$ Division of Clinical Epidemiology, Department of Clinical Research and Informatics, National Center for Global

Health and Medicine, Tokyo, Japan

${ }^{2}$ Department of Public Health, Kitasato University School of Medicine, Sagamihara, Kanagawa, Japan

${ }^{3}$ Department of Mental Health, Tokyo University Graduate School of Medicine, Tokyo, Japan

${ }^{4}$ Health Administration and Psychosocial Factor Research Group, National Institute of Occupational Safety and

Health, Kawasaki, Kanagawa, Japan

${ }^{5}$ Department of Mental Health, Institute of Industrial Ecological Sciences, University of Occupational and Environ-

mental Health, Kitakyushu, Fukuoka, Japan

${ }^{6}$ Graduate School of Business, Osaka City University, Sugimoto Sumiyoshi-ku, Osaka-shi, Japan

${ }^{*}$ Corresponding author: Miyaki K, Department of Clinical Research and Informatics, National Center for Global Health and Medicine, Shinjuku-ku, Tokyo, Japan, Fax: +81 33202 7364, Tel: +81 33202 7181, E-mail: miyaki-keio@umin.net

Citation: Miyaki K, Suzuki T, Song Y, Tsutsumi A, Kawakami N, et al. (2015) Epigenetic Changes Caused by Occupational Stress in Humans Revealed through Noninvasive Assessment of DNA Methylation of the Tyrosine Hydroxylase Gene. J Neurol Neurol Disord 2(2): 201. doi: 10.15744/2454-4981.2.201. doi: $10.15744 / 2454-4981.2 .201$

Received Date: February 12, 2015 Accepted Date: June 24, 2015 Published Date: June 26, 2015

\begin{abstract}
Tyrosine hydroxylase $(\mathrm{TH})$ catalyzes the rate-limiting step in the synthesis of L-dihydroxyphenylalanine (L-DOPA), a precursor of dopamine, and is considered to be involved in many aspects of mental health. On the other hand, the epigenetic mechanisms have been recognized as mediators of stable changes in brain function. A recent study showed that mild isolation stress in adolescent mice induced epigenetic control of dopaminergic neurons via glucocorticoids, which enhanced DNA methylation of the $T H$ gene. It is reasonable to presume that this $\mathrm{TH}$ gene hypermethylation could also be a stress marker in humans, particularly for occupational stress, as several people report suffering from increased stress in the workplace. Mental health cohort data were used to assess the DNA methylation status of the human $T H$ gene. A total of 774 DNA samples were extracted from saliva and classified into 4 groups according to individual job strain scores. Ninety samples of each group were selected randomly (360 subjects in total) and 4 DNA pools were constructed. The Illumina Human Methylation 450K Microarray system was used to examine the DNA methylation patterns in the whole TH gene, as well as promoter region, using these pooled samples. Our observations showed that DNA methylation levels of the $T H$ promoter region were significantly higher in subjects with high stress, as evaluated based on a validated job strain questionnaire $\left(\mathrm{p}=7.14 \times 10^{-9}\right)$. Furthermore, DNA methylation levels of the whole human $\mathrm{TH}$ gene were also elevated in individuals with higher stress scores $\left(\mathrm{p}=2.48 \times 10^{-6}\right)$ in an additive manner. These results revealed the increased methylation levels in salivary peripheral leukocyte DNA with increased job stress, indicating that DNA methylation estimation has potential as an effective and objective stress marker. Keywords: Tyrosine Hydroxylase Gene; DNA Methylation; Human Methylation 450K Microarray; Stress; Job Strain

List of Abbreviations: TH: Tyrosine hydroxylase; L-DOPA: L-dihydroxyphenylalanine; J-HOPE: Japanese Study of Health, Occupation, and Psychosocial Factors Related Equity; JDCS: Job Demand-Control-Support; TE: Tris-EDTA; EDTA: Ethylene diaminetetraacetic acid; IL-6: interleukin-6; JCQ: Job Content Questionnaire; ERI: Effort Reward Imbalance
\end{abstract}

\section{Introduction}

Depression is a common illness and the leading cause of disability throughout the world, with an estimated 350 million people affected, and is a major contributor to the global disease burden [1]. Depression results from complex interactions of social, psychological, and biological factors, and occupational stress is one of the key contributing factors to depression $[2,3]$. In occupational stress studies, three major components are used to describe workplace qualities: demands, control, and support, and the Job Demand-Control-Support (JDCS) model is adopted widespread [4]. Job stress factors are generally measured via selfadministered questionnaire [4], however, the difficulty in objectively assessing occupational stress is a priority issue in research related to treatment of depression. 
With advances in medical science, epigenetics has attracted interest in several fields, including mental health since the plasticity of DNA methylation has been suggested to account for some of the essential mechanisms underlying the mood fluctuations that occur in depression via gene-environment $(\mathrm{G} \times \mathrm{E})$ interactions. Recent explorations of the epigenetic basis of depressive disorder have identified the involvement of DNA methylation of several genes with mental health, such as the Brain-Derived Neurotrophic Factor [5], Serotonin Transporter [6], and Catechol-O-Methyltransferase [7] genes.

According to the "Monoamine Hypothesis" of depression, monoamine neurotransmitters, including catecholamines (dopamine, norepinephrine, and epinephrine) and serotonin [8], play a key role in the pathophysiology of depression [9,10]. Tyrosine hydroxylase $(\mathrm{TH})$ is an enzyme that catalyzes the initial and rate-limiting step in catecholamine biosynthesis, i.e., the conversion of L-tyrosine to L-dihydroxyphenylalanine (L-DOPA) [11]. Catecholamines are a class of neurotransmitters that are implicated in a various array of physiological processes associated with mental health. Therefore, expression of the $\mathrm{TH}$ gene is functionally important, and accordingly, this gene region and its regulatory sequences, including cAMP responsive element, activator proteins, and the E-box in its promoter region, are highly conserved [12]. Epigenetic mechanisms, which involve DNA and histone modifications, result in the heritable silencing of genes without a change in their coding sequence [13]. Promoter methylation has been demonstrated to correlate with many disease states, leading to reduced gene expression as example [14]. A recent epigenetic study in adolescent mice showed that mild isolation stress affects the mesocortical projection of dopaminergic neurons in which DNA hypermethylation (elevated methylation) of the TH gene is considered a genetic risk for neuropsychiatric disorders [15].

We previously investigated human mental health and its contributing factors in a large occupational cohort study (Japanese Study of Health, Occupation, and Psychosocial Factors Related Equity; J-HOPE) [16-19]. Since there is little evidence about epigenetic changes in the human $T H$ gene in response to stress, we aimed to elucidate the DNA methylation state of the human $T H$ gene in a non-invasive manner by referring to occupational cohort data that includes information on both validated stress markers [20$22]$ and a depression score $[23,24]$. In the current study, we examined the methylation status in CpG loci located along the whole human TH gene, and the 5' flanking region up to 11 kilo bases away from the transcription start site, because a previous study suggested that potential recognition sites for several transcription factors are included in this region [25].

\section{Methods}

\section{Subjects}

J-HOPE is a national level, large-scale occupational cohort study on social class and health in Japanese workers involving more than ten thousand employees representing a number of different industries [16-19]; the study was initiated in 2009 and designed as a 5-year follow-up survey. For the current study, workers of a major manufacturing company with offices spread all over Japan were recruited. All workers were invited to participate in this study, and 774 agreed to provide their saliva samples (mean age 43.4 \pm 9.8 years; 75 females). Nobody of the participants has any medical history of psychiatric disorders. The protocol and explanation documents of our study were approved by the ethics committees of the National Center for Global Health and Medicine and the University of Tokyo School of Medicine, and all participants provided written informed consent.

\section{Sample Collection}

Each subject was first asked to deliver approximately $2 \mathrm{~mL}$ of saliva into an Oragene kit according to the instructions for use included with the kit (DNA Genotec; Ontario, Canada) [26]. Shortly after collection, the Oragene/saliva samples were mixed by shaking for 15 seconds and then stored at room temperature. The genomic DNA was extracted from leukocytes by using the Oragene DNA Self-Collection Kit User Instructions, OG-500 Tube Format (DNA Genotec; Ontario, Canada) [26]. All of the DNA samples were diluted to a working concentration of $20 \mathrm{ng} / \mu \mathrm{L}$ with TE buffer $(10 \mathrm{mMTris}, 1 \mathrm{~m}$ Methylene diaminetetraacetic acid (EDTA).

\section{Assessment}

The age, sex, height, weight, blood pressure, fasting blood glucose, serum lipid level, serum concentrations of interleukin-6 (IL-6) and C-reactive protein, and smoking and alcohol consumption status were collected during health checkups for all subjects. Body mass index was calculated by dividing the weight (in $\mathrm{kg}$ ) by the height squared (in meters). The degree of depressive symptoms was assessed using the Japanese version of Kessler's K6 questionnaire [23,24]. Subjects were divided into quartile groups based on their overall job strain scores determined by job demands and job control. Job demands and job control were assessed using the corresponding subscale of the Japanese version of the Job Content Questionnaire (JCQ) [4,20], consisting of 5 and 9 items, respectively. Each item was scored on a four-point scale, ranging from 1 to 4 , and responses to each item were summed to create the scale scores. The job strain score is defined as the ratio of job demands to job control multiplied by 2 in order to adjust for the difference in scoring ranges between the job demand scale (12-48) and the job control scale (24-96) [27]. Years of education, annual household income, and job position were assessed by a self-administered questionnaire as described above.

Based on a validation study demonstrating that a DNA pool generated with 89 individual samples can provide an accurate and reliable quantitative estimate of average group DNA methylation levels [28], four independent pools were formed from $901-\mu \mathrm{L}$ DNA samples randomly selected from each job strain quartile group. Thus, a total volume of $90 \mu \mathrm{L}$ corresponding to a total amount 
of $1.8 \mu \mathrm{g}$ of DNA was evaluated for each pool. Genome-wide DNA methylation profiling was performed using Illumina Inifium Human Methylation 450 Bead Chip arrays and kit (Illumina; San Diego, CA). Four microliters of bisulfite-converted DNA was used for hybridization onto the Human Methylation450 BeadChip, following the Illumina Inifium HD Methylation protocol.

\section{Data Analysis}

The IlluminaiScan SQ scanner was used to create images of the single arrays, and intensities of the images were evaluated using GenomeStudio (v.2011.1) Methylation module (v.1.9.0) software. The methylation levels were measured quantitatively using methylated and unmethylated signal intensity of each job strain quartile. The methylation score is represented as the ratio of methylated to methylated plus unmethylated signal intensity.

We calculated the methylation levels for every CpG site individually, as well as the average methylation levels of all $28 \mathrm{CpG}$ sites and all CpG sites in the promoter region only, for each of the four pools. Then, methylated and unmethylated signal intensity between the lowest (Q1) and highest (Q4) job strain quartiles were compared using Pearson's chi-square test. Furthermore, Pearson's chi-square test was used to evaluate the difference in the average $\beta$ values of the merged CpG sites among all four quartiles. The IBM SPSS Statistics for Windows version 19.0J (IBM; Armonk, NY, USA) statistics software packages were used for all statistical analyses. Statistical significance for all analyses was defined as $\mathrm{p}<0.05$.

\section{Results}

A total of 360 subjects were selected from the 4 job strain groups to form the DNA pools, 32 of which were women. The basic clinical characteristics, K6 score, job strain, and socioeconomic status factors (education level, household income, and job position) of these subjects are shown in Table 1 , and the mean ( \pm standard deviation) values of these indices were compared among job strain groups. Only systolic blood pressure and years of education were found to be significantly different among the 4 groups ( $\mathrm{p}$-value for trend test $<0.05$ ).

There are a total of $28 \mathrm{CpG}$ sites spread throughout the human $T H$ gene and the 5 ' flanking region (Figure 1), which can be detected by the Infinium Human Methylation 450 Bead Chip. Of these sites, 22 are located within exons or introns (Nos. 1-22 in Figure 1), 4 are located in the promoter region (Nos. 23-26), and 2 are located in the 5 ' flanking region of this gene approximately 11,000 bases away from the transcription start site (Nos. 27-28). The DNA methylation status was examined for all 28 loci in each pool. The methylation levels of the lowest job strain group (Q1) and the highest job strain group (Q4) were compared. DNA methylation levels of the Q4 group were significantly higher than those of the Q1 group in 12 loci and were significantly lower in 7 loci (Table 2), and 5 loci showed differences greater than 5\% (Nos. 4, 7, 14, 15, 24). The average methylation levels of the 28 loci in the Q4 group were $66.3 \%$ and 67.0\%, respectively, the chi-square test showed that the ratio of methylated signals in the Q4 group was significantly higher than that in the Q1 group $\left(\mathrm{p}=2.48 \times 10^{-6}\right.$, Table 3$)$, suggesting that the DNA methylation level in the TH gene is significantly greater in individuals experiencing stronger occupational stress. Focusing on the promoter region $200 \mathrm{bp}$ upstream of the transcription start site, which corresponds to the promoter region of the mouse $\mathrm{TH}$ gene analyzed in the previous study [15], the average methylation levels for CpG site Nos. 23-25 of the Q1 and Q4 groups were 63.9\% and 66.9\%, respectively, which remained significantly different (chi-square test, $\mathrm{p}=7.14 \times 10^{-9}$ ). Furthermore, considering two upstream loci far from the transcription start site, Nos.27 and 28, the difference was even greater; the average methylation levels for CpG loci 23-28 of the Q1 and Q4 group were 74.8\% and 76.8\%, respectively $\left(\mathrm{p}=1.01 \times 10^{-11}\right)$. In addition, the average values for the 28 loci of the four job stress groups Q1-Q4 were $0.673,0.675,0.678$, and 0.689 , respectively, showing an additive relationship of DNA methylation levels with stress score, although it was not statically significant by a regression analysis (Standardized coefficient $=0.024, \mathrm{P}=$ 0.801) (Figure 2).

Hypermethylation of the TH gene under conditions of high stress was also confirmed using another validated stress marker, the Effort Reward Imbalance (ERI) index $\left(\mathrm{p}=3.67 \times 10^{-2}\right)$.

\begin{tabular}{|c|c|c|c|c|c|}
\hline & \multicolumn{4}{|c|}{ Job strain } & \multirow{2}{*}{$P$ for trenc } \\
\hline & $1^{\text {st }}$ quartile (Lowest) & $2^{\text {nd }}$ quartile & $3^{\text {rd }}$ quartile & $4^{\text {th }}$ quartile (Highest) & \\
\hline Age (year) & $43.5 \pm 11.0$ & $43.8 \pm 8.7$ & $44.2 \pm 9.5$ & $44.3 \pm 9.4$ & 0.577 \\
\hline Proportion of women (\%) & 10.0 & 11.1 & 8.9 & 5.6 & 0.589 \\
\hline Body mass index $\left(\mathrm{kg} / \mathrm{m}^{2}\right)$ & $22.8 \pm 2.6$ & $22.9 \pm 2.8$ & $22.6 \pm 2.9$ & $23.0 \pm 3.2$ & 0.962 \\
\hline Systolic blood pressure (mmHg) & $128.6 \pm 16.9$ & $124.4 \pm 14.7$ & $120.9 \pm 15.9$ & $121.0 \pm 15.7$ & $0.001^{*}$ \\
\hline Diastolic blood pressure $(\mathrm{mmHg})$ & $79.5 \pm 12.6$ & $77.0 \pm 11.8$ & $75.5 \pm 13.0$ & $76.9 \pm 12.0$ & 0.139 \\
\hline Serum total cholesterol (mg/dL) & $210.1 \pm 72.0$ & $191.4 \pm 32.5$ & $195.1 \pm 28.9$ & $204.9 \pm 34.9$ & 0.773 \\
\hline Serum triglyceride $(\mathrm{mg} / \mathrm{dL})$ & $209.9 \pm 780.1$ & $118.1 \pm 109.9$ & $119.8 \pm 122.0$ & $139.5 \pm 172.2$ & 0.360 \\
\hline $\begin{array}{l}\text { Serum high-density lipoprotein } \\
\text { cholesterol (mg/dL) }\end{array}$ & $62.5 \pm 15.3$ & $62.4 \pm 16.5$ & $62.8 \pm 17.6$ & $62.9 \pm 18.6$ & 0.856 \\
\hline Fasting plasma glucose (mg/dL) & $101.6 \pm 28.1$ & $90.7 \pm 20.5$ & $93.2 \pm 16.5$ & $97.9 \pm 26.2$ & 0.585 \\
\hline
\end{tabular}




\begin{tabular}{|c|c|c|c|c|c|}
\hline & \multicolumn{4}{|c|}{ Job strain } & \multirow{2}{*}{$P$ for trenc } \\
\hline & $1^{\text {st }}$ quartile (Lowest) & $2^{\text {nd }}$ quartile & $3^{\text {rd }}$ quartile & $4^{\text {th }}$ quartile (Highest) & \\
\hline Serum IL-6 (pg/mL) & $1.7 \pm 2.6$ & $1.4 \pm 0.7$ & $1.3 \pm 0.9$ & $1.4 \pm 1.2$ & 0.178 \\
\hline Serum C-reactive protein $(\mu \mathrm{g} / \mathrm{mL})$ & $579.2 \pm 1149.8$ & $509.5 \pm 690.1$ & $425.2 \pm 524.6$ & $824.7 \pm 2032.7$ & 0.346 \\
\hline Years of education (year) & $15.4 \pm 2.2$ & $14.8 \pm 2.6$ & $15.0 \pm 2.6$ & $14.5 \pm 2.6$ & $0.019^{*}$ \\
\hline $\begin{array}{c}\text { Annual household income (ten } \\
\text { thousands yen/year) }\end{array}$ & $693.9 \pm 296.7$ & $731.1 \pm 274.6$ & $731.7 \pm 291.7$ & $665.6 \pm 279.8$ & 0.532 \\
\hline $\begin{array}{l}\text { Proportion of individuals in a man- } \\
\text { agement position (\%) }\end{array}$ & 31.1 & 24.4 & 21.1 & 21.1 & 0.355 \\
\hline K6 Score & $5.3 \pm 5.3$ & $4.8 \pm 4.9$ & $5.7 \pm 5.7$ & $4.6 \pm 4.3$ & 0.602 \\
\hline Job strain score & $1.0 \pm 0.4$ & $2.3 \pm 0.3$ & $3.5 \pm 0.4$ & $7.6 \pm 3.5$ & $<0.001^{* *}$ \\
\hline Proportion of current smokers (\%) & 26.7 & 25.6 & 18.9 & 28.9 & 0.803 \\
\hline $\begin{array}{c}\text { Proportion of subjects with Habitual } \\
\text { drinking (\%) }\end{array}$ & 78.9 & 71.1 & 71.1 & 75.3 & 0.429 \\
\hline
\end{tabular}

Values are shown as mean \pm standard deviation or percentage. For continuous variables linear regression analysis was used, and for categorized variables Pearson's chi-square test was used to compare indices between the 4 job strain groups. ${ }^{*} \mathrm{P}<0.05,{ }^{*} \mathrm{P}<0.01$

Table 1: Comparison of clinical characteristics, depressive scores, job stress, and socioeconomic status among subjects in 4 job strain group

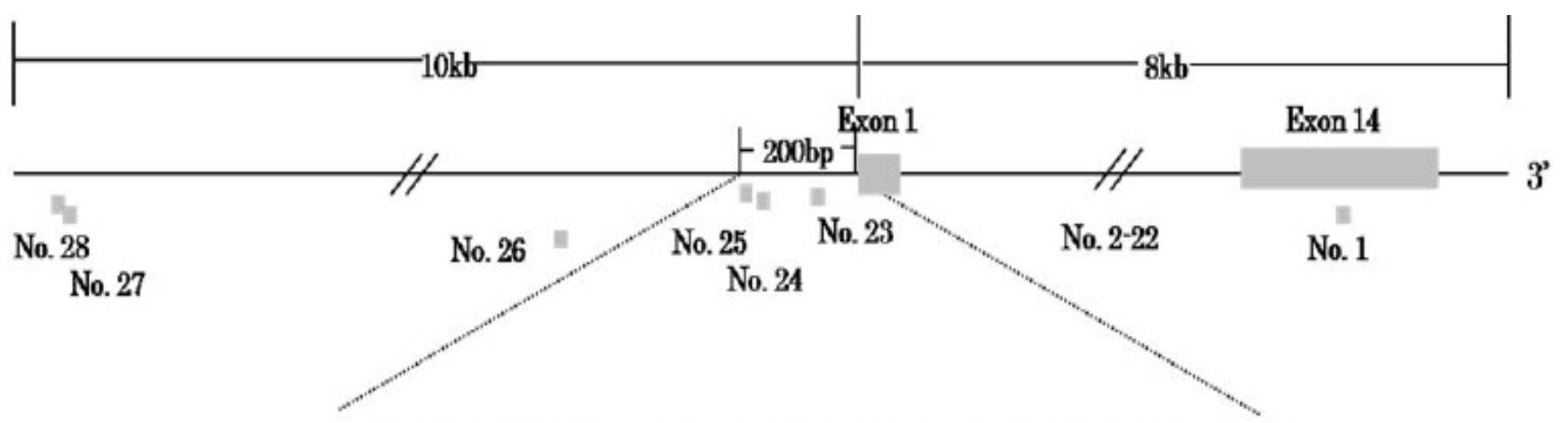

\section{CTGTCTCAGCCCCCCGCAGAGCACGAGCCCCTGGTCCCCGCAAGCCCGCGGG \\ No. 25 No. 24 \\ CTGAGGATGATTCAGACAGGGCTGGGGAGTGAAGGCAATTAGATTCCACGGA}

\section{CGAGCCCTTTCTCCTGCGCCTCCCTCCTTCCTCACCCACCCCCGCCTCCATCA \\ No. 23 \\ GGCACAGCAGGCAGGGGTGGGGGATGTAAGGAGGGGAAGGTGGG}

Figure 1: Schematic representation of the human TH gene and the CpG loci analyzed

The whole human TH gene and the 5' flanking region up to 11,000 bp from the transcription start site are shown. The line in the center represents the chromosome. Small square boxes: CpGs analyzed; big square boxes: exons of the TH gene; the sequence of the region from nucleotides -200 to -1 (numbers are relative to the transcription start site, considered as +1 ) is shown below the line in which CpG sites 23-25 are located and are underlined

\begin{tabular}{|c|c|c|c|c|c|}
\hline \multirow{3}{*}{ CpG site No. } & \multirow{3}{*}{ ID of IlluminaCpG sites } & \multirow{3}{*}{ Location in the gene } & \multicolumn{2}{|c|}{ DNA Methylation } & \multirow{3}{*}{$P$ value } \\
\hline & & & $1^{\text {st }}$ quartile & $4^{\text {th }}$ quartile & \\
\hline & & & (Lowest job strain, \%) & (Highest job strain, \%) & \\
\hline 21 & $\operatorname{cg} 05912121$ & Exon 1 & 83 & 81 & $4.59 \times 10^{-3^{* *}}$ \\
\hline 22 & $\operatorname{cg} 08573687$ & Exon 1 & 98 & 96 & $6.26 \times 10^{-13^{* *}}$ \\
\hline 16 & $\operatorname{cg} 08560888$ & Exon 3 & 94 & 96 & $1.19 \times 10^{-3^{* *}}$ \\
\hline 13 & $\operatorname{cg} 15572496$ & Exon 4 & 62 & 63 & 0.073 \\
\hline 6 & $\operatorname{cg} 16844661$ & Exon 8 & 74 & 73 & 0.151 \\
\hline 4 & $\operatorname{cg} 21191514$ & Exon 9 & 24 & 39 & $1.29 \times 10^{-73^{* *}}$ \\
\hline 1 & $\operatorname{cg} 26966083$ & Exon 14 & 76 & 73 & $5.73 \times 10^{-6^{* *}}$ \\
\hline 17 & $\operatorname{cg} 09199250$ & Intron 2-3 & 88 & 85 & $7.70 \times 10^{-13^{* *}}$ \\
\hline 18 & $\operatorname{cg} 14803762$ & Intron 2-3 & 77 & 79 & $1.92 \times 10^{-2^{*}}$ \\
\hline 19 & $\operatorname{cg} 01516872$ & Intron 2-3 & 27 & 28 & 0.078 \\
\hline 20 & cg14714364 & Intron 2-3 & 81 & 80 & 0.37 \\
\hline 14 & $\operatorname{cg} 19125767$ & Intron 3-4 & 62 & 69 & $6.63 \times 10^{-11^{* *}}$ \\
\hline
\end{tabular}




\begin{tabular}{|c|c|c|c|c|c|}
\hline \multirow{3}{*}{ CpG site No. } & \multirow{3}{*}{ ID of IlluminaCpG sites } & \multirow{3}{*}{ Location in the gene } & \multicolumn{2}{|c|}{ DNA Methylation } & \multirow{3}{*}{$P$ value } \\
\hline & & & $1^{\text {st }}$ quartile & $4^{\text {th }}$ quartile & \\
\hline & & & (Lowest job strain, \%) & (Highest job strain, \%) & \\
\hline 15 & $\operatorname{cg} 16003049$ & Intron 3-4 & 71 & 81 & $2.16 \times 10^{-17^{* *}}$ \\
\hline 8 & $\operatorname{cg} 26464934$ & Intron 4-5 & 86 & 86 & 0.501 \\
\hline 9 & $\operatorname{cg} 25150846$ & Intron 4-5 & 99 & 97 & $9.68 \times 10^{-22^{* *}}$ \\
\hline 10 & $\operatorname{cg} 26969596$ & Intron 4-5 & 100 & 98 & $5.60 \times 10^{-16^{* *}}$ \\
\hline 11 & $\operatorname{cg} 23042775$ & Intron 4-5 & 59 & 60 & $2.73 \times 10^{-2^{*}}$ \\
\hline 12 & $\operatorname{cg} 18226539$ & Intron 4-5 & 68 & 68 & 0.697 \\
\hline 7 & $\operatorname{cg} 00358132$ & Intron 7-8 & 72 & 81 & $4.42 \times 10^{-34^{* *}}$ \\
\hline 5 & $\operatorname{cg} 23951474$ & Intron 8-9 & 60 & 60 & 0.876 \\
\hline 2 & $\operatorname{cg} 19878200$ & Intron $10-11$ & 11 & 13 & $7.38 \times 10^{-3^{* *}}$ \\
\hline 3 & $\operatorname{cg} 14149680$ & Intron $10-11$ & 2 & 2 & 0.214 \\
\hline 23 & $\operatorname{cg} 25011257$ & 5' upstream (Promoter) & 58 & 60 & $9.71 \times 10^{-3^{* *}}$ \\
\hline 24 & $\operatorname{cg} 05141787$ & 5' upstream (Promoter) & 62 & 70 & $2.00 \times 10^{-12^{* *}}$ \\
\hline 25 & $\operatorname{cg} 21644468$ & 5' upstream (Promoter) & 73 & 74 & 0.499 \\
\hline 26 & $\operatorname{cg} 04204669$ & 5' upstream (Promoter) & 65 & 67 & $4.27 \times 10^{-3^{* *}}$ \\
\hline 27 & $\operatorname{cg} 27626334$ & 5' upstream & 86 & 89 & $5.05 \times 10^{-7^{* *}}$ \\
\hline 28 & cg07419975 & 5' upstream & 96 & 95 & $7.68 \times 10^{-3^{* *}}$ \\
\hline
\end{tabular}

$P$ values show the significance for the Pearson's chi-square test.

Job strain score is defined as the ratio of job demands to job control multiplied by 2 .

${ }^{* \mathrm{P}}<0.05,{ }^{* * \mathrm{P}}<0.01$

Table 2: Comparison of quantitative DNA methylation values for CpG sites on the human TH gene between the pools of the first and fourth job strain quartiles

\begin{tabular}{|c|c|c|c|c|c|}
\hline \multirow{2}{*}{ CpG sites included } & \multirow{2}{*}{ Stress (job strain) } & & \multicolumn{2}{|c|}{ DNA Methylation } & \multirow{2}{*}{$P$ value } \\
\hline & & & unmethylated & methylated & \\
\hline \multirow{4}{*}{$\begin{array}{c}\text { Sites } \\
23 \text { to } 25 \text { merged } \\
\text { (promoter region only) }\end{array}$} & \multirow{2}{*}{$4^{\text {th }}$ quartile (highest) } & Signal intensity (n) & 5228 & 10564 & \multirow{4}{*}{$7.14 \times 10^{-9}$} \\
\hline & & $(\%)$ & $33.1 \%$ & $66.9 \%$ & \\
\hline & \multirow{2}{*}{$1^{\text {st }}$ quartile(lowest) } & Signal intensity (n) & 6494 & 11490 & \\
\hline & & $(\%)$ & $36.1 \%$ & $63.9 \%$ & \\
\hline \multirow{4}{*}{$\begin{array}{l}\text { Sites } \\
1 \text { to } 28 \text { merged } \\
\text { (all CpG sites) }\end{array}$} & \multirow{2}{*}{$4^{\text {th }}$ quartile (highest) } & Signal intensity (n) & 65219 & 132234 & \multirow{4}{*}{$2.48 \times 10^{-6}$} \\
\hline & & $(\%)$ & $33.0 \%$ & $67.0 \%$ & \\
\hline & \multirow{2}{*}{$1^{\text {st }}$ quartile(lowest) } & Signal intensity (n) & 73320 & 144114 & \\
\hline & & $(\%)$ & $33.7 \%$ & $66.3 \%$ & \\
\hline
\end{tabular}

The chi-square test was used to compare differences in methylation values between the pools of 1st (lowest) and 4th (highest) job strain quartile

Table 3: Average DNA methylation values for the CpG sites on the human TH gene in the pools of the first and fourth job strain quartiles

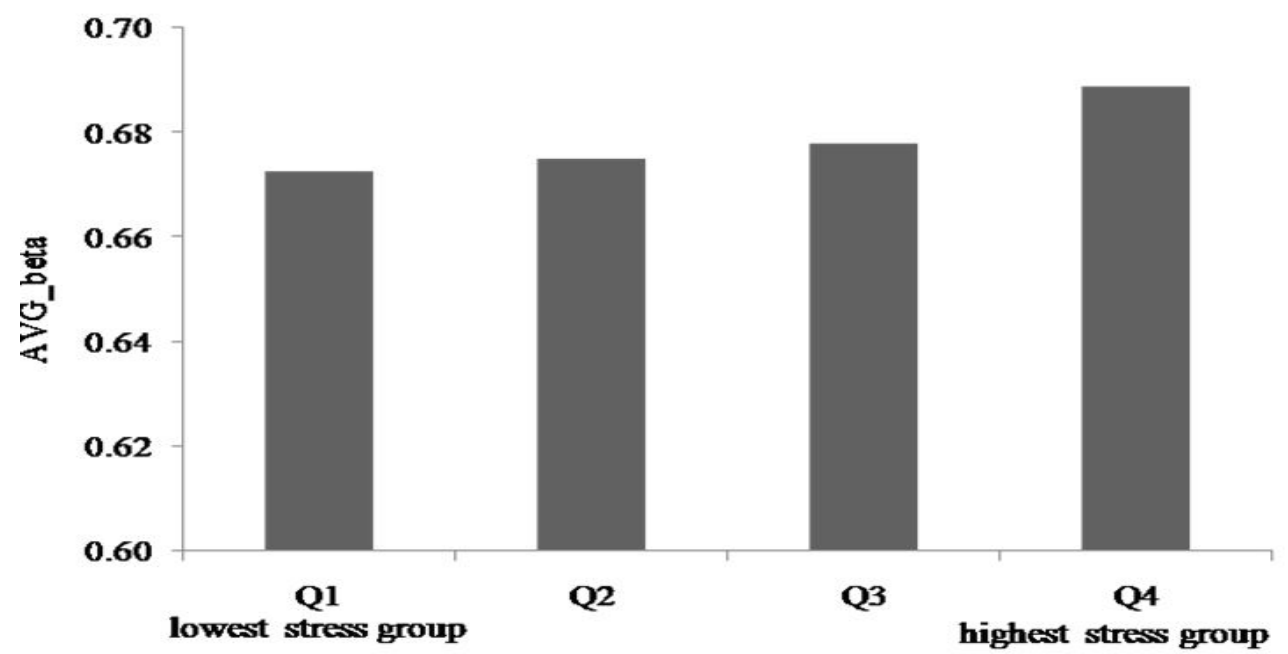

Figure 2: The relationship between DNA methylation status and job strain quartiles

The longitudinal axis presents the average $\beta$ values of $28 \mathrm{CpG}$ sites on the human TH gene in four pools formed by 90 DNA samples extracted from job strain quartiles. The mean values and standard errors of average $\beta$ values of the 4 job strain groups are shown 


\section{Discussion}

In the current study, Infinium Human Methylation 450K technology was used to obtain a high-throughput methylation profile of the human genome. The new high-density BeadChip can assay over 480,000CpG sites, and provides coverage of $99 \%$ of RefSeqgenes with multiple probes per gene and $96 \%$ of $\mathrm{CpG}$ islands throughout the whole genome. DNA methylation profiles generated by this array were shown to be comparable with those obtained using conventional sequencing methods (average $\left.\mathrm{R}^{2}=0.95\right)$ [29]. This approach was also confirmed to be powerful in terms of reagent cost, time of labor, sample throughput, and coverage [30].

In our study in humans, we obtained the similar result as that of a recent study in adolescent mice showing that mild isolation stress during adolescence resulted in epigenetic changes of the TH gene [15]. To our knowledge, our study is the first to investigate the association of DNA methylations on the TH gene with occupational stress in humans. DNA methylation levels of the whole human $\mathrm{TH}$ gene were significantly elevated in individuals with relatively higher job strain $\left(\mathrm{p}=2.48 \times 10^{-6}\right)$. Furthermore, DNA methylations of the promoter region of the human $\mathrm{TH}$ gene, which corresponds to the same region investigated in the mouse study [15], were also significantly elevated in individuals experiencing high job stress $\left(\mathrm{p}=7.14 \times 10^{-9}\right)$.

$\mathrm{TH}$ is encoded by the $\mathrm{TH}$ gene, and the enzyme is involved in the catalysisof catecholamine (monoamine) biosynthesis [11]. A previous study reported that stress in a mouse model enhanced DNA methylation of the TH gene. We here found that DNA methylations of the human THgene are also significantly elevated in response to high stress, despite species differences. Furthermore, the methylation levels were found to be elevated by high stress in an additive manner; higher job strain was associated with increased methylation state of the $T H$ gene (Figure 2). There is no universally accepted theory that slight difference in methylation would lead to a different expression. However, it is possible to affect the expression via small change of methylation biologically. On the other hand, methylation levels of cg21191514, cg00358132, cg19125767 and cg16003049 in the exons/intron region were significantly elevated in individuals experiencing high job stress. Therefore, these CpG sites could be possible marker. Further studies are needed. By contrast, in general, methylation and gene expression are typically thought to show an inverse correlation, such that increased methylation corresponds to decreased gene expression and vice versa [13]. However, Uddin et al. reported that some processes (e.g. brain development, tryptophan metabolism) showed patterns suggestive of increased methylation among individuals with depression whereas others (e.g. lipoprotein) showed patterns suggestive of decreased methylation among individuals with depression [31]. As stated above, it could be resulted in that DNA methylation levels in 7 Loci of TH gene were lower in subjects with high stress.

This time, we focused on $T H$ gene as biologically-important gene to avoid producing false positive results from multiple comparisons. A global methylation analysis would be interesting. DNA methylation levels of the highest job strain group (Q4) were significantly higher than those of the lowest job strain group (Q1) $(44.8 \%$ versus $44.5 \%, \mathrm{P}<0.001)$. However, it was considered that the difference has no medical significance because a comparison of a huge sample showed statistically a significant difference.

Concerning years of education (Table 1), the difference in years of education among 4 groups of job strain was considered to be not clinically-significant because of slight difference although the difference were statistically-significant. On the other hand, it was considered that it was possible that many years of education cause an elevated stress, and thus, elevated methylation profile. Concerning systolic blood pressure (Table 1), the systolic blood pressure was higher in 1st quartile than 4th quartile although in the 1st quartile are less stressed than 4th quartile. Possible mechanism was considered that blood pressure could go up a little adversely in normal level under the environment of poor stimulation.

The strength of our study is the high reliability of cohort data that were collected longitudinally and using validated questionnaires. These occupational stress indices, job strain [4,20,27,32,33] and ERI [21,34-36], have been confirmed to reflect acceptable levels of reliability and validity. The JCQ, based on Karasek's demand-control model [4], has been one of the most popular instruments designed to assess the psychosocial work environment [37]. It is the most widely used workplace environment questionnaire, and is currently available in over 12 languages [38]. The validity of the JCQ has been assessed for various languages, including English, Dutch, and Japanese [32].

Nevertheless, it is difficult to objectively assess stress in humans because most conventional methods depend on self-administered questionnaires. By contrast, the DNA methylation level is a quantitative measure that is notself-administered. The methylation level represents the ratio of the intensity of methylated to total (methylated plus unmethylated) signal outputs. Therefore, our results provide strong support that estimation of the DNA methylation levels in specific regions of the human genome could serve as an effective and objective marker for some psychiatric factors, including stress.

There are some limitations in the current study. First, stress comes in a variety of different forms. In the previous mouse study, isolation stress was assessed during adolescence, whereas occupational stress in adulthood was evaluated in the present study. Job strain $[4,20,27,32,33]$ and ERI [21,34-36], which have been established internationally as reliable stress factor indices for occupational stress, was measured in the present study using a validated questionnaire in Japanese. Job strain was measured using the JCQ scale [4,20,27,32,33] and ERI was measured using the Effort Reward Imbalance Questionnaire scale [21,34-36]. Results of previous and our studies have indicated that DNA methylations of the $T H$ gene were elevated by stress in each age category. Second, in the previous study, DNA samples were extracted directly from tissues of the midbrain [15]. It was reported that the stress only affected the mesocortical projection of dopaminergic neurons in which DNA hypermethylation of the $T H$ gene is 
elicited, but did not affect the mesolimbic projection of dopaminergic neurons [15]. Therefore, two distinct dopaminergic projections (mesocortical and mesolimbic) were differentially affected in the mouse. By contrast, in the present study, we analyzed methylation levels of the TH gene from DNA extracted from salivary peripheral leukocytes, which move through the bloodbrain barrier. Therefore, although our method cannot distinguish between the mesocortical and mesolimbic projections of dopaminergic neurons, it was selected because of its non-invasiveness, thereby facilitating a clinical study using living people. Our results showed that estimating DNA methylations of the $T H$ gene from salivary peripheral leukocyte DNA could be an effective and objective stress marker in humans. Although DNA is also easily obtained from blood, it is necessary to establish home-based and noninvasive methods of DNA collection in order to carry out large epidemiological studies; saliva collection is a safe and easy means of DNA collection. In addition, it has been demonstrated that salivasamples are a viable alternative to blood samples as a source of DNA for high-throughput genotyping [39], and DNA methylation patterns in saliva are relatively consistent with those in whole blood [40]. Furthermore, the method used for sample collection in the current study, a whole-saliva collection device, provided a significantly greater DNA yield than other established non-invasive methods (e.g., cytobrush, foam swab, and oral rinse) [41].

\section{Conclusion}

In conclusion, our study provides new evidence that epigenetic regulations are associated with increased job stress. Although further studies are necessary to confirm our results, wide application of our method and accumulation of this type of objective evidence could help to prevent depression or suicide for people who might have had a disadvantaged childhood.

\section{Acknowledgment}

The present study was supported by a Grant-in-Aid for Scientific Research (B) (No. 24390160) from the Ministry of Education, Culture, Sports, Science, and Technology, Japan (Chief: Dr. Koichi Miyaki), by a Grant-in-Aid for Scientific Research on Innovative Areas (Research in a Proposed Research Area) (No. 21119001) from the Ministry of Education, Culture, Sports, Science and Technology, Japan (Chief: Dr. Norito Kawakami) and by JSPS KAKENHI Grant Number 26253042.

\section{References}

\section{WHO (2012) Fact sheet Nº369 October.}

2. Wang J (2005) Work stress as a risk factor for major depressive episode(s). Psychol Med 35: 865-71.

3. Siegrist J (2008) Chronic psychosocial stress at work and risk of depression: evidence from prospective studies. Eur Arch Psychiatry Clin Neurosci 258: 115-9.

4. Karasek, Robert A (1979) Job demands, job decision latitude, and mental strain: implications for job redesign. Adm Sci Q 24: 285-308.

5. Fuchikami M, Morinobu S, Segawa M, Okamoto Y, Yamawaki S, et al. (2011) DNA methylation profiles of the brain-derived neurotrophic factor (BDNF) gene as a potent diagnostic biomarker in major depression. PLoS One 6: e23881.

6. Philibert RA, Sandhu H, Hollenbeck N, Gunter T, Adams W, et al. (2008) The relationship of 5HTT (SLC6A4) methylation and genotype on mRNA expression and liability to major depression and alcohol dependence in subjects from the Iowa Adoption Studies. Am J Med Genet B Neuropsychiatr Genet 147B: 543-9.

7. Murphy BC, O’Reilly RL, Singh SM (2005) Site-specific cytosine methylation in S-COMT promoter in 31 brain regions with implications for studies involving schizophrenia. Am J Med Genet B Neuropsychiatr Genet 133B: 37-42.

8. Kurian MA, Gissen P, Smith M, Heales S Jr, Clayton PT (2011) The monoamine neurotransmitter disorders: an expanding range of neurological syndromes. Lancet Neurol 10: 721-33.

9. Bunney WE Jr, Davis JM (1965) Norepinephrine in depressive reactions. A review. Arch Gen Psychiatry 13: 483-94.

10. Schildkraut JJ (1995) The catecholamine hypothesis of affective disorders: a review of supporting evidence. 1965. J Neuropsychiatry Clin Neurosci 7: 523-4.

11. Kim KS, Tinti C, Song B, Cubells JF, Joh TH (1994) Cyclic AMP-dependent protein kinase regulates basal and cyclic AMP-stimulated but not phorbol esterstimulated transcription of the tyrosine hydroxylase gene. J Neurochem 63: 834-42.

12. Arányi T, Faucheux BA, Khalfallah O, Vodjdani G, Biguet NF, et al. (2005) The tissue-specific methylation of the human tyrosine hydroxylase gene reveals new regulatory elements in the first exon. J Neurochem 94: 129-39.

13. Egger G, Liang G, Aparicio A, Jones PA (2004) Epigenetics in human disease and prospects for epigenetic therapy. Nature 429: 457-63.

14. El-Osta A, Wolffe AP (2000) DNA methylation and histone deacetylation in the control of gene expression: basic biochemistry to human development and disease. Gene Expr 9: 63-75.

15. Niwa M, Jaaro-Peled H, Tankou S, Seshadri S, Hikida T, et al. (2013) Adolescent stress-induced epigenetic control of dopaminergic neurons via glucocorticoids. Science 339: 335-9.

16. Miyaki K, Song Y, Htun NC, Tsutsumi A, Hashimoto H, et al. (2012) Folate intake and depressive symptoms in Japanese workers considering SES and job stress factors: J-HOPE study. BMC Psychiatry 12: 33.

17. Miyaki K, Song Y, Taneichi S, Tsutsumi A, Hashimoto H, et al. (2013) Socioeconomic status is significantly associated with dietary salt intakes and blood pressure in Japanese workers (J-HOPE Study). Int J Environ Res Public Health 10: 980-93.

18. Miyaki K, Song Y, Taneichi S, Tsutsumi A, Hashimoto H, et al. (2013) Socioeconomic status is significantly associated with the dietary intakes of folate and depression scales in Japanese workers (J-HOPE Study). Nutrients 5: 565-78.

19. Song Y, Miyaki K, Suzuki T, Sasaki Y, Tsutsumi A, et al. (2014) Altered DNA methylation status of human brain derived neurotrophis factor gene could be useful as biomarker of depression. Am J Med Genet B Neuropsychiatr Genet 165B: 357-64.

20. Kawakami N, Kobayashi F, Araki S, Haratani T, Furui H (1995) Assessment of job stress dimensions based on the job demands- control model of employees of telecommunication and electric power companies in Japan: reliability and validity of the Japanese version of the Job Content Questionnaire. Int J Behav Med 2: $358-75$. 
21. Siegrist J, Starke D, Chandola T, Godin I, Marmot M, et al. (2004) The measurement of effort-reward imbalance at work: European comparisons. Soc Sci Med 58: 1483-99.

22. Niedhammer I, Tek ML, Starke D, Siegrist J (2004) Effort-reward imbalance model and self-reported health: cross-sectional and prospective findings from the GAZEL cohort. Soc Sci Med 58: 1531-41.

23. Kessler RC, Andrews G, Colpe LJ, Hiripi E, Mroczek DK, et al. (2002) Short screening scales to monitor population prevalences and trends in non-specific psychological distress. Psychol Med 32: 959-76.

24. Sakurai K, Nishi A, Kondo K, Yanagida K, Kawakami N (2011) Screening performance of K6/K10 and other screening instruments for mood and anxiety disorders in Japan. Psychiatry Clin Neurosci 65: 434-41.

25. Kessler MA, Yang M, Gollomp KL, Jin H, Iacovitti L (2003) The human tyrosine hydroxylase gene promoter. Brain Res Mol Brain Res 112: 8-23.

26. Birnboim HC (2004) DNA yield with Oragene ${ }^{\text {тx }}$ [Internet]. Ottawa: DNA Genotek, Inc.

27. Kawakami N, Tsutsumi A, Haratani T, Kobayashi F, Ishizaki M, et al. (2006) Job strain, worksite support, and nutrient intake among employed Japanese men and women. J Epidemiol 16: 79-89.

28. Docherty SJ, Davis OS, Haworth CM, Plomin R, Mill J (2009) Bisulfite-based epityping on pooled genomic DNA provides an accurate estimate of average group DNA methylation. Epigenetics Chromatin 2: 3.

29. Bibikova M, Barnes B, Tsan C, Ho V, Klotzle B, et al. (2011) High density DNA methylation array with single CpG site resolution. Genomics 98: 288-95.

30. Dedeurwaerder S, Defrance M, Calonne E, Denis H, Sotiriou C, et al. (2011) Evaluation of the Infinium Methylation 450K technology. Epigenomics 3: 771-84.

31. Uddin M, Koenen KC, Aiello AE, Wildman DE, de los Santos R, et al. (2011) Epigenetic and inflammatory marker profiles associated with depression in a community-based epidemiologic sample. Psychol Med 41: 997-1007.

32. Karasek R, Brisson C, Kawakami N, Houtman I, Bongers P, et al. (1998) The Job Content Questionnaire (JCQ): an instrument for internationally comparative assessments of psychosocial job characteristics. J Occup Health Psychol 3: 322-55.

33. Karasek R, Theorell T (1992) Healthy Work: Stress, Productivity, and the Reconstruction of Working Life. Basic Books, New York.

34. Siegrist J (1996) Adverse health effects of high-effort/low-reward conditions. J Occup Health Psychol 1: 27-41.

35. Tsutsumi A, Kawakami N (2004) A review of empirical studies on the model of effort-reward imbalance at work: reducing occupational stress by implementing a new theory. Soc Sci Med 59: 2335-59.

36. Tsutsumi A, Ishitake T, Peter R, Siegrist J, Matoba T (2001) The Japanese version of the Effort-Reward Imbalance Questionnaire: a study in dental technicians. Work Stress 15: 86-96.

37. Hurrell JJ Jr, Nelson DL, Simmons BL (1998) Measuring job stressors and strains: where we have been, where we are, and where we need to go. J Occup Health Psychol 3: 368-89.

38. Sale JE, Kerr MS (2002) The psychometric properties of Karasek's demand and control scales within a single sector: data from a large teaching hospital. Int Arch Occup Environ Health 75: 145-52.

39. Abraham JE, Maranian MJ, Spiteri I, Russell R, Ingle S, et al. (2012) Saliva samples are a viable alternative to blood samples as a source of DNA for high throughput genotyping. BMC Med Genomics 5: 19.

40. Thompson TM, Sharfi D, Lee M, Yrigollen CM, Naumova OY, et al. (2013) Comparison of whole-genome DNA methylation patterns in whole blood, saliva, and lymphoblastoid cell lines. Behav Genet 43: 168-76.

41. Rogers NL, Cole SA, Lan HC, Crossa A, Demerath EW (2007) New saliva DNA collection method compared to buccal cell collection techniques for epidemiological studies. Am J Hum Biol 19: 319-26.

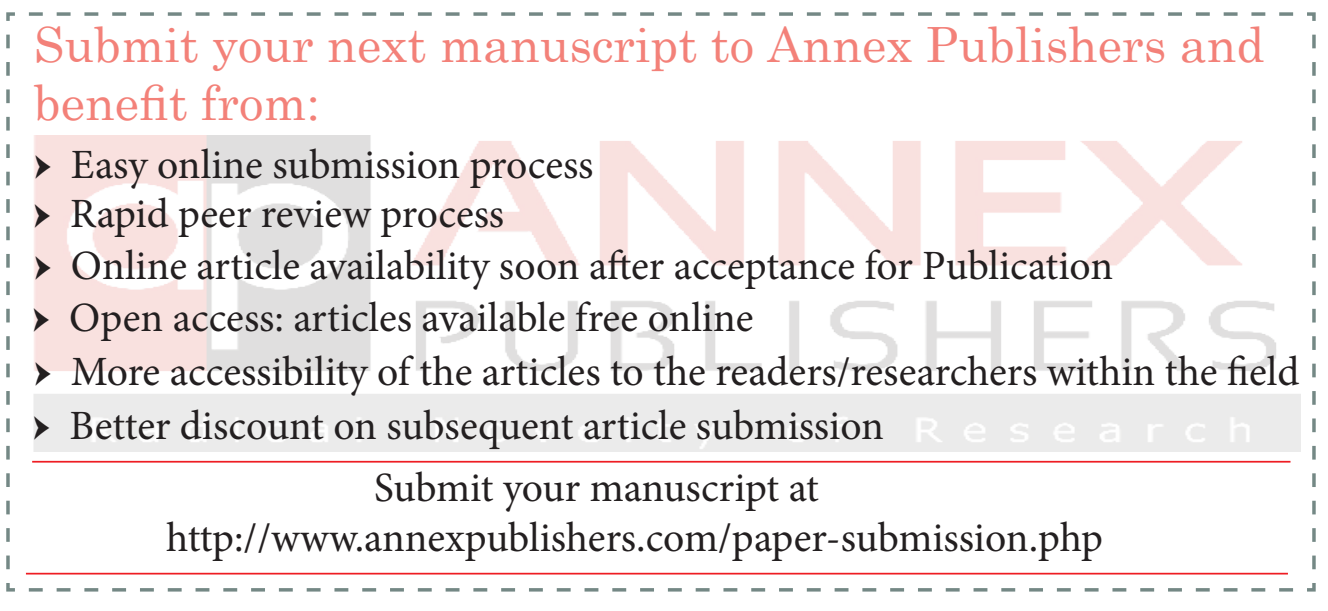

